\title{
Aspectos materiais da informalidade como recurso urbano: o caso das favelas do Rio de Janeiro
}

\section{Material aspects of informality as an urban resource: the case of Rio de Janeiro's favelas}

\author{
Rafael Soares Gonçalves \\ Advogado e historiador. Professor do Departamento de Serviço \\ Social da PUC-Rio, Brasil \\ rafaelsg@puc-rio.br
}

\section{Resumo}

$\mathrm{O}$ artigo procura analisar os desdobramentos materiais de práticas informais na cidade do Rio de Jneiro nos últimos anos. Para isso, centra sua reflexão sobre como a informalidade permite práticas de construções mais flexíveis, modulando, através da autoconstrução, a habitação de acordo com as necessidades familiares. Da mesma forma, analisa a gestão informal de certos serviços coletivos, assim como a delimitação oficial das áreas de favela através do estudo da aplicação de medidas de isenção fiscal para os alvarás comerciais nesses espaços. O estudo desses três casos busca compreender como os moradores adaptaram suas práticas informais às suas necessidades, de forma a compreender paradoxalmente a informalidade como uma função social, já que permite a parte considerável da população do Rio de Janeiro de acessar à cidade e seus recursos. Considera-se, por fim, que as políticas públicas para as favelas cariocas devem partir de uma reflexão mais detalhada sobre as práticas informais, baseando-se também no imenso recurso que essas iniciativas representam.

Palavras-chave: Informalidade urbana - favelas - autoconstrução - serviços coletivos

\begin{abstract}
The article seeks to analyze the material unfolding of informal practices at Rio de Janeiro in the last years. It focuses on how informality allows more flexible building practices, modulating selfconstruction and housing to family needs. Likewise, it analyses the informal management of certain collective services and the official delimitation of favela areas through the study of the application of tax exemption measures for commercial permits in these spaces. The study of these three cases seeks to understand how residents have adapted their informal practices to their needs to understand informality as a social function paradoxically. It allows a considerable part of Rio de Janeiro's population to access the city and its resources. Finally, it is considered that public policies for Rio's favelas should start from a more detailed reflection on informal practices, also based on the immense resource that these initiatives represent.
\end{abstract}

Keywords: Urban informality; favelas; self-construction; collective services.

\section{INTRODUÇÃO}

Os recursos disponíveis na cidade não são distribuídos de forma equitativa. Os serviços coletivos, tais como água, electricidade e transportes são cada vez mais entendidos como produtos de mercado e não como direito de todos. A instalação e distribuição de tais recursos são elementos intrínsecos à própria urbanidade e necessários para a reprodução social dos seus habitantes. As 
formas de acesso, partilha e regulação desses recursos estão no centro do processo de produção do espaço urbano e diretamente relacionados à noção de direito à cidade (LEFEBVRE, 2001). Tal direito pressupõe o acesso aos recursos urbanos, assim como a capacidade dos citadinos de participarem ativamente da produção da cidade como uma obra coletiva. Em um contexto de privatizações generalizadas dos serviços coletivos no Brasil, é necessário conceber os recursos urbanos como bens comuns e compreender as lógicas que regem sua regulamentação e utilização (OSTROM, 1990).

A reflexão sobre a produção social do espaço permite-nos compreender que a localização privilegiada de deteminado localidade pode se configurar como um recurso em si, permitindo acesso distinto a outros potenciais recursos. A configuração do espaço desempenha, assim, um papel instrumental e político e constitui e reproduz estruturas de poder. $\mathrm{O}$ recurso advindo de uma localização específica na cidade se traduz obviamente em termos econômicos e é diretamente apropriado, por exemplo, pelo mercado imobiliário, que extrai de determinação localização sua mais-valia. Assim, os custos econômicos da habitação são diretamente proporcionais à sua localização, que garante aos habitantes o acesso aos recursos urbanos, ou seja, como sustenta Kowarick (1975), numa sociedade de classes a oportunidade de obter recursos raros não se distribui ao acaso.

Nesse contexto, o presente artigo pretende analisar o papel da informalidade urbana neste processo de configuração e acesso aos recursos urbanos e, em última análise, na influência da informalidade na produção do próprio espaço urbano. A informalidade não deve ser necessariamente entendida como algo irregular, ilegal, marginal ou fora do alcance do Estado, como estipulado pelos teóricos da marginalidade (HARRINGTON, 1963; VILLAR et al., 1970 e LEWIS, 1972). ${ }^{1}$ Existe uma longa literatura crítica à associação da informalidade à marginalidade (NÉLISSE e MOULIN, 1994; ROY e ALSAYYAD, 2003; JACQUOT et al., 2016; BAUTES et al., 2016; BOUDREAU et al., 2016; MACFARLANE, 2016; LUSSAULT, 2016; GONÇALVES et al., 2018 e BANKS et al., 2020). Tais estudos resignificam o próprio papel do Estado, que não está de modo algum ausente dos espaços informais e, em muitos casos, tem sido um dos principais atores no processo de desenvolvimento e consolidação destas áreas. Assim, como sublinha Haid (2017, p. 290), a informalidade deve ser analisada também e necessariamente como produção do Estado.

Da mesma forma, não existe uma demarcação clara entre formal e informal. Segundo Jacquot et al., (2016), por exemplo, o termo informal não deve ser entendido como um termo negativo do formal, implicando que não tem forma e, portanto, nenhuma regra. De acordo com Jacquot et al., (2016), o informal parece estar mesclado ao formal, produzindo uma variedade de

\footnotetext{
${ }^{1}$ Há uma vasta e pioneira literatura sobre as favelas cariocas crítica às teorias da marginalidade: Machado, 1967; Conn, 1969; Leeds e Leeds, 1978; Perlman, 1981 e Valladares, 2000.
} 
regimes de planejamento e organização social da cidade de acordo com o grau de práticas nãopadronizadas que contêm. Nesse mesmo sentido, Banks et al., (2020, p. 224) sublinham a importância de estudar a informalidade não pelas lacunas em relação ao que seria o formal, mas pela habilidade de seus atores em selecionar, na própria informalidade, o que lhes pode ser vantajoso. Assim, compreender a informalidade como um local estratégico de análise crítica dos diferentes atores questiona compreensões dualistas - formal versus informal - dessa realidade, assim como permite dar significado ao continuum amplamente fluido e variável entre formal e informal.

A informalidade poderia ser caracterizada também como uma forma de produção do espaço, uma forma de planejamento e exercício de poder e regulação. Não é necessariamente uma organização extra-legal (ROY, 2009b: p. 84), mas que dialoga com as práticas do próprio Estado em suas margens (DAS e POOLE, 2004). Rolnik (2015, p. 217) corrobora parcialmente com este pensamento quando defende que as categorias de posse presentes nas áreas informais são frequentemente parcialmente formais, reconhecidas ou legais, e geram áreas cinzentas e combinações distintas de legalidade e formalidade. Na mesma direção, Lussault também indica que os espaços informais não estão sem ordem e regulamentação (LUSSAULT, 2016, p. 32). Esta indefinição de categorias, como afirma Jacquot et al., (2016), deriva em primeiro lugar de práticas informais dos agentes públicos, que encarnam a regra e que impregnam o governo da cidade com suas lógicas.

Defendemos, aqui, que a informalidade não é, portanto, o grande problema urbano, locus por excelência de pobreza e marginalidade. Tampouco defendemos que a informalidade seja a solução de planejamento urbano ou um conjunto de práticas necessariamente insurgentes. Este tipo de reflexão pode conduzir a uma generalização por vezes superficial de tais práticas. Há, por certo, práticas clientelistas e violentas, assim como a apropriação privada de recursos locais, em alguns casos mediado por grupos mafiosos de todo tipo (BENMERGUI e GONÇALVES, 2019), sabendo, evidentemente, que tal realidade não é absolutamente uma prerrogativa dos espaços considerados informais, uma vez que se manifestam também em áreas ditas formais. Devemos, pois, afastar-nos de uma compreensão dualista do conceito de informalidade urbana, que o consideraria ou como um problema ou como uma solução. É preciso, por outro lado, admitir que a informalidade é uma realidade urbana e, como defendemos aqui, exerce uma função social.

Em trabalhos anteriores, analisamos (GONÇALVES, 2013) que as intervenções públicas nas favelas do Rio até o final dos anos 1970 se baseavam em uma espécie de "tolerância precária", que admitia intervenções esporádicas nestas áreas sem as reconhecer de fato. Essa tolerância procurava manter os aspectos provisórios e precários das favelas, o que impactou diretamente nos aspectos materiais desses espaços. Embora a precariedade fundiária das favelas levou historicamente a estigmatização dos seus habitantes (SANTOS, 1977), desestimulou também o interesse de grandes 
grupos imobiliários em investir nestas áreas. A informalidade permitiu, assim, o acesso à cidade a um grande contingente populacional, que jamais poderia usufruir de uma moradia, muitas vezes em bairros centrais, através do mercado imobiliário formal ou de políticas públicas de habitação social, que historicamente priorizam a produção de moradia em áreas distantes e isoladas, onde justamente o acesso a certos recursos urbanos é comprometido. Como argumenta MacFarlane (2016, p. 66), práticas quotidianas, consideradas informais, podem constituir em si mesmas recursos úteis que os indivíduos lançam mão para realizar alguns dos seus projetos (MACFARLANE, 2016, p. 66).

Mesmo nos precavendo de discursos simplistas, que promovam a informalidade necessariamente como a solução urbana para as nossas cidades, este artigo é, contudo, provocador, já que procura compreender como a informalidade pode significar, em certos contextos urbanos, um recurso em si mesmo, assegurando aos seus moradores o acesso aos diferentes recursos urbanos. Procuraremos analisar a informalidade como um processo e como repercute nos aspetos propriamente materiais das favelas. As espacialidades quotidianas dos bairros informais, como sublinha Macfarlane (2011, p. 659), refletem o processo do incremento habitacional através de um processo de justaposição sucessiva de materiais e intenções de seus habitantes.

Esse entendimento vem ao encontro da noção defendida por Carvalho (2015, p. 316) de empilhamento de serviços. Ao analisar a construção de uma capela na favela do Borel, a autora constata que esse espaço concentra e reflete uma superposição da presença do Estado através de serviços muitas vezes já inexistentes, mas que ainda marcam o espaço e a memória dos moradores. Para Carvalho (2015, p. 316), a noção de empilhamento seria um processo de acumulação de práticas sociais no espaço. Ora, a materialidade das construções em favelas obedece a um planejamento, onde materiais e intenções dos distintos atores locais interagem, modulado por temporalidades variáveis e superpostas. A imprevisibilidade da vida ganha contornos no construído e naquilo que, por alguma razão, ainda falta construir. A produção do espaço urbano é por vezes estável, por vezes precário, o que realça, na materialidade desses locais, continuidades e descontinuidades do cotidiano de seus moradores.

Com base nos vários trabalhos de investigação que realizamos nos últimos anos nas favelas do Rio de Janeiro e a partir de uma releitura de artigo anterior (GONÇALVES, 2017), procuramos, aqui, analisar os desdobramentos materiais de práticas informais. A primeira parte deste artigo centra-se na reflexão de como a informalidade permite práticas de construções mais flexíveis, modulando, através da auto-construção, a habitação de acordo com as necessidades familiares. O artigo analisa, posteriormente, como a gestão informal de certos serviços coletivos podem, por vezes, dar origem a formas elaboradas de organização coletiva, mais adaptadas às demandas locais. A última secão abordará a delimitação oficial das zonas de favela através do estudo da aplicação de medidas de isenção fiscal para os alvarás comerciais nesses espaços. Se, por um lado, tal legislação 
reforça as representações negativas das favelas e reproduz o entendimento da favela como algo pretensamente transitório, por outro lado, beneficia diretamente quem mora nas favelas com a isenção de taxas. Como veremos nos três casos elencados, os moradores adaptam suas práticas informais às suas necessidades, o que nos traz o questionamento sobre a função social exercida pela informalidade na garantia para parte considerável da população do Rio de Janeiro de acessar à cidade e seus recursos.

\section{AUTOCONSTRUÇÃO INFORMAL COMO UM RECURSO URBANO}

No Brasil, a autoconstrução está diretamente associada a uma das facetas do desenvolvimento urbano. Maricato, citando Francisco de Oliveira, explica que essa forma de produção de moradia levou a uma redução nos salários. Segundo a autora, este aspecto revela que a modernização e o desenvolvimento capitalista seria tributário de um modo de produção prémoderno, ou mesmo pré-capitalista (autoconstrução de casas) em parte da cidade (MARICATO, 2015, p. 26-27). A afirmação de que a autoconstrução é um elemento específico do desenvolvimento urbano nos países em desenvolvimento não leva em conta o fato dessa lógica também ter se manifestado em outros contextos. É interessante notar que as diferentes formas de ocupação da periferia das cidades europeias nas primeiras décadas do século XX não foram muito diferentes das periferias brasileiras e latino-americanas. Em várias cidades europeias, é possível perceber também um estatuto precário da terra, formas diversas de negociações políticas para a consolidação de bairros periféricos e um amplo processo de autoconstrução de casas, como demonstrado, por exemplo, pelos trabalhos de Vorms (2012) sobre Madrid, Fourcaut (2000) para Paris ou Bartolini (2001) em relação à Roma .

Desde os anos 1960, autores como Mar (1962), Mangin (1967) e Turner (1972) têm considerado que a ocupação de áreas informais não é um obstáculo à aculturação urbana ou mesmo uma barreira à mobilidade socioeconómica, conforme sustentado pelos teóricos da marginalidade. De acordo com Turner (1972, p. 269), a menos que estas áreas sejam cuidadosamente qualificadas, é impossível definições generalizantes, como aquelas associadas à cultura da pobreza (LEWIS, 1972). Seria um erro, como argumenta Lussault, considerar a priori que os bairros informais são socialmente homogéneos (LUSSAULT, 2016, p. 31). Uma vez que a ocupação de terrenos era historicamente considerada ilegal, as moradias construídas simplesmente não tinham uma existência oficial e, como resultado, as autoridades não tratavam esses moradores como os demais habitantes da cidade.

Neste contexto, as mobilizações políticas nas favelas do Rio têm-se voltado, desde o início do século XX, para a luta pela permanência de seus residentes. O principal objetivo destas 
manifestações era a consolidação das favelas na cidade. As primeiras associações de residentes, que começaram a se institucionalizar ainda nos anos 1920, baseavam-se na questão da instalação local de melhoramentos diversos (GONÇALVES, 2013). A luta pela habitação estava mais relacionada com a melhoria local do que com a luta para a formulação de políticas públicas de fornecimento de habitação social, ou seja, a localização fazia parte da estratégia de inserção na cidade. Não bastava lutar por uma moradia, mas pela moradia e localidade que auto-construíam.

No entanto, a melhoria das casas através da gradual auto-construção foi historicamente comprometida por uma política deliberada de "congelamento urbano" (GONÇALVES, 2012), que consistia em proibir a melhoria das casas para manter justamente o aspecto precário e provisório das construções, de forma que se pudesse erradicá-las a qualquer momento. Isso se manifestou, inclusive, com a proibição expressa de construção de casas em alvenaria (GONÇALVES, 2013). Só nos anos 80 , quando finalmente se consolidaram as políticas de urbanização das favelas, é que construções mais sólidas se generalizaram, estimulados pela garantia que seus moradores não seriam mais despejados. ${ }^{2}$ Podemos utilizar a reflexão de Korling (2020, p. 25) para o caso da cidade africana de Niamey, quando afirma que a estabilidade material em espaços considerados informais oferece um importantes senso de segurança, mesmo com a ausência de títulos de propriedade. No caso do Rio de Janeiro, a mobilização política desde então priorizou a luta por melhorias e, mais recentemente, contra a violência policial em detrimento de lutas por títulos e, por última instância, pela formalização desses locais.

A descrição das favelas nos censos nos permite compreender a evolução material de suas construções. O censo de 1950 descrevia as casas em favelas como "casebres ou barracões de aspecto rústico típico, construídos principalmente de folhas de flandres, e napas zincadas, tábuas ou materiais semelhantes" (GUIMARÃES, 1953. p. 259). Essa descrição foi reproduzida no censo de 1960, já o censo de 1970 atualiza os materiais construtivos das habitações. Em vez das "folhas de flandres e napas zincadas" dos censos de 1950 e 1960, o Censo de 1970 descreve os barracos com a utilização principalmente "de folhas de metal, madeira não aparelhada, material de embalagem usado" (IBGE, 1970). Os aspectos materiais construtivos das residências deixam de ser, pouco a pouco, considerados como elementos diferenciadores desses espaços e foram excluídos da definição de favelas à partir do censo de 1980. Isso reflete provavelmente o progressivo aumento das construções em alvenaria nas favelas. As definições das áreas faveladas vão se voltar mais para a descrição do espaço do que das unidades habitacionais, destacando sempre as pretensas lacunas das favelas em relação ao restante da cidade (GONÇALVES, 2020).

\footnotetext{
${ }^{2}$ A partir do relatório do Instituto de Pesquisa de Mercado/IPEME (1957), Gonçalves (2013) demonstra que muitas favelas mais periféricas já possuíam um número importante de casas construídas em alvenaria. A política pública de controle das construções variava de acordo com o bairro onde estavam situadas as favelas, ou seja, o controle era muito mais rígido nas favelas situadas nos bairros centrais e mais nobres da cidade.
} 
No contexto de uma pesquisa realizada em 2012 sobre a relação entre os habitantes de uma pequena favela na Zona Sul do Rio de Janeiro e o Parque Nacional da Tijuca, pudemos seguir a lógica subjacente à organização da construção de uma casa de uma família nesta favela. A história dessa construção traz elementos interessantes para compreender esse acúmulo de práticas sociais no espaço construído. A família em questão era tradicional e bem conhecida na favela. A casa tem um bom acabamento interior e ainda mantém bela uma vista para as árvores, o que é raro nas favelas, que se tornaram densamente povoadas nos últimos anos, e na qual muitas construções já possuem vários pavimentos.

A utilização de casas e quartos para aluguel tornou-se generalizada na favela mencionada acima, especialmente para satisfazer a grande procura de estudantes com bolsas de estudo de uma universidade próxima e prestigiada da cidade. Viver nesta favela oferece-lhes não só a proximidade da universidade, mas também o privilégio de viver na Zona Sul, perto da praia e de vários recursos urbanos, tais como transporte, equipamentos de saúde, grande oferta de trabalho e lazer. Mesmo com a presença de traficantes e com o aumento dessa atividade nos últimos anos, a favela ainda não é considerada um mercado importante de drogas, especialmente quando comparada com outras favelas da vizinhança.

Retomamos o contato com essa família no mês de julho de 2020 para nos atualizarmos sobre os desdobramentos da construção da casa. Maria (nome fictício) nos relatou que seu pai comprou o terreno com "um barraco" por volta do ano de 1960. Ela morou nesse barraco até o início dos anos 1980. Só o banheiro e a cozinha tinham partes em alvenaria, o restante da casa era de madeira. Quando chovia, ela conseguia ver a lama por baixo das tábuas de maneira, sem contar o vento que passava entre as frestas das paredes. A sua descrição da casa parecia com as definições do censo de 1970 mencionada anteriormente. Maria nos relatou, ainda, que só ergueram a casa em alvenaria à partir do início dos anos 1980, "depois do Brizola." ${ }^{3}$ Ela nos contou que a casa, assim como muitas na favela, eram erguidas por mutirão com a participação de familiares e vizinhos. A mãe de Maria foi presidente da associação dos moradores nos anos 1980 e só permitia que erguessem um segundo andar na favela. No entanto, já à partir do início dos anos 1990, não existia mais esse controle. Seu pai decide continuar a construção da casa com quatro andares (porão, dois andares e a laje).

Após a morte do pai de Maria, em 2010 ( sua mãe tinha morrido alguns anos antes), Maria e seus quatro irmãos decidem partilhar a casa. Duas irmãs cederam suas partes, pois já tinham

\footnotetext{
${ }^{3}$ Leonel Brizola governou o Estado do Rio de Janeiro pela primeira vez entre os anos de 1983-1987 e implementou uma série de políticas voltadas para a urbanização e redução da violência policial nas favelas. Apesar de intervenções concomitantes dos demais entes federativos nas favelas, o governo Brizola ficou mais fortemente associado às demandas populares, sobretudo das favelas. As políticas de urbanização deram segurança aos moradores para investirem na melhoria de suas casas.
} 
moradia. Uma das irmãs assumiu o porão e o vendeu. Maria cedeu o primeiro andar - onde já morava com sua família, pois ficou cuidando do seu pai na velhice - ao seu irmão, que tinha dificuldade de subir as escadas. Ela ficou, assim, com o segundo andar da casa, que ainda não tinha os acabamentos internos realizados. Como deveria finalizar a obra, ganhou o direito de usar a laje no terceiro andar. Maria decidiu fechar a escada interna da casa e refez um acesso pelo quintal, criando uma entrada exclusiva para a sua casa no segundo andar. Como acredita que a estrutura de toda a construção pode ser prejudicada se construir mais um andar na laje, decidiu fazer uma área aberta para churrascos com um quartinho para alugar, mas sem nova laje. Após alguns anos de obras intermitentes, o casal se mudou para um bairro distante por exigências do trabalho e por receios com o aumento de conflitos entre a polícia e o tráfico de drogas. Continua usando a casa a cada tanto, mas as obras foram por enquanto paralisadas.

Podemos notar que toda a construção é pontuada pela disponibilidade de recursos financeiros e novas necessidades que podem variar ao longo do tempo. Não se trata, aqui, de fazer propriamente uma etnografia das lógicas e estratégias de construção nas favelas, como foi feito, por exemplo, por Cavalcanti (2009). A autora afirma, que houve, desde o início dos projetos de urbanização de favelas à partir do início dos anos 1980, um boom de construção nas favelas com forte aumento do mercado imobiliário informal. Ela argumenta que a auto-construção das moradias é um fato social total, ou seja, é uma chave analítica para compreender a realidade social atual desses espaços. Em termos jurídicos, Conn (1969), Santos (1974), Franco (2012) e Magalhães (2013) deram importantes contribuições para a compreensão das formas de gestão jurídica nas favelas do Rio. Como se pode observar nas obras citadas, as práticas informais são complexas, menos institucionalizadas e mais adaptadas às necessidades dos residentes.

No caso mencionado acima, as práticas informais permitiram a partilha da propriedade, concederam a possibilidade de rendimentos adicionais à família pelo aluguel e, finalmente, expandiram a oferta de habitação a preços mais acessíveis em zonas privilegiadas da cidade. Podemos, evidentemente, questionar a gestão destas áreas ao longo do tempo. A expansão do mercado imobiliário informal nos últimos anos trouxe uma dinâmica bem distinta dos mutirões citados por Maria, provocando, por vezes, uma concentração de imóveis nas mãos de certos grupos privilegiados, muitas vezes com relações ambiguas com grupos mafiosos locais. Da mesma forma, não se observa mais o controle exercido pela associação de moradores sobre o número de pavimentos, conforme nos descreveu Maria. Se a construção vertical de moradias mantém a oferta de moradias relativamente mais acessível, provoca, por outro lado, uma intensa densificação do ambiente construído e que pode trazer impactos para a saúde dos moradores, como se observou durante o debate sobre a pandemia do coronavírus nas favelas. Enfim, o processo de construção da casa de Maria e, de maneira mais ampla, a própria lógica da auto-construção de moradias, dialoga 
com a reflexão de Macfarlane (2011, p. 651) sobre a espacialidade da habitação, quando afirma que a cidade não é somente o lugar habitado, mas aquele que é produzido enquanto habitado.

\section{REDES INFORMAIS DE ACESSO A SERVIÇOS COMUNITÁRIOS}

A informalidade torna-se, segundo Roy (2009a, p. 826), um modo de subjetividade, uma forma inteligente de operar em cidades com poucos recursos. Para além de um conjunto de aço e cimento, as infra-estruturas devem ser entendidas como um campo de ação e consolidação de redes sociais. As ofertas de serviços alternativos desenvolvem-se normalmente nos interstícios do serviço do operador oficial ou mesmo na negação de atendimento de certos grupos seja por questões econômicas ou por estarem associados à ilegalidade. Apesar de um certo grau de padronização através da reprodução de comportamentos semelhantes, as práticas de oferta informal de serviços coletivos continuam a ser heterogêneas e, muitas vezes ainda artesanais (JAGLIN e ZÉRAH, 2010, p. 16).

Alain (2011, p. 380) sublinha a importância de uma nova reflexão sobre a economia informal, uma reflexão que permita que ela seja vista para além de uma única prática desorganizada, como é classicamente descrita. $\mathrm{O}$ autor procura compreender práticas informais no âmbito da gestão adaptativa e integrada, de acordo com o pensamento dos ecologistas canadenses Crawford Stanley Holling e Carl Walters, que se baseia no conceito central de resiliência. Guha-khasnobis, Kanbur e Ostrow (2006, p. 2), por sua vez, relatam que, ao longo dos anos 1990, surgiu a ideia de trabalhar os arranjos informais a partir da perspectiva de regimes de propriedades comuns. Além disso, em termos de discurso político, a associação da informalidade ao caos e à desestruturação tem sido uma força poderosa para todo tipo de intervenções que têm conduzido repetidamente a resultados desastrosos (Op. Cit., 2006, p. 7).

Descreveremos,brevemente a experiência de acesso à água na favela da Formiga, localizada na Zona Norte da cidade. ${ }^{4}$ Ora, é antigo o problema do abastecimento de água no Rio de Janeiro. A população sempre sofreu com a falta de um sistema de qualidade, especialmente a população mais pobre. A água é um elemento central da vida e a luta para obtê-la faz parte da vida quotidiana dos habitantes das favelas do Rio. Dada a proibição de conectar as casas das favelas à rede pública, até os anos 1980, por estarem localizadas em zonas consideradas ilegais, a mobilização dos favelados se voltou historicamente para a instalação de bicas d'água (GONÇALVES et al., 2015). Estas bicas tornaram-se lugares centrais nas favelas, onde os residentes vinham buscar água várias vezes ao dia

\footnotetext{
${ }^{4}$ Nos anos de 2014 e 2015, entrevistamos vários moradores desta favela e acompanhamos as reuniões mensais e as diversas atividades levadas a cabo pela Sociedade da Água Bela Vista. Esta favela possui dezenas de sociedades de água, que captam água do Parque Nacional da Tijuca e a distribuem aos seus associados. A Companhia Bela Vista tem quinze membros e existe desde 1949.
} 
e onde as lavadeiras passavam o dia trabalhando. A instalação das bicas d'água era uma forma dos poderes públicos prestarem um serviço coletivo sem reconhecer oficialmente estes espaços, configurando o que já denominamos anteriormente como política de tolerância precária das favelas (GONÇALVES, 2013).

Além das formas de acesso à água descrito acima, vários sistemas cooperativos de captação e distribuição de água já existiam nas favelas no período pós-guerra, conforme afirmam Leeds e Leeds (1978, p. 115). Naquelas favelas localizadas no entorno da Serra da Carioca, muitas redes de captação de água da Floresta da Tijuca foram instaladas pelos próprios moradores (SILVA, GONÇALVES e SANCHEZ, 2018). No que diz respeito à falta de água, organizaram as chamadas Sociedades de Água, que são "grupos de pessoas que se reuniam em torno de uma nascente, cuja água dividiam, zelando por ela e pelo abastecimento dos associados" (PANDOLFI e GRYNSPAN, 2003, p. 13).

No caso da favela da Formiga, como existiam inúmeras nascentes no morro, os moradores as procuravam na mata e quem as encontrasse em primeiro adquiria o direito de usá-la. Há inúmeras sociedades de água, com número variado de associados e com maior ou menor grau de organização interna. De forma coletiva, essas sociedades recolhem água na mata, constroem um reservatório e dali a água é distribuída para as diferentes casas dos associados. ${ }^{5}$ São responsáveis também pela manutenção destas redes alternativas de distribuição de água. Apesar de termos observado também alguns casos de captação privada de nascentes do parque e mesmo a comercialização do serviço de abastecimento na favela, a grande maioria das redes existentes ou são individuais ou são redes associativas coletivas no formato das sociedades de água.

Um exemplo é a Sociedade de àgua Bela Vista, criada ainda em 1949. Os residentes juntaram-se e adquiriram todo o equipamento necessário para a construção do reservatório e da rede. ${ }^{6}$ Esta sociedade, juntamente com várias outras na favela da Formiga, ainda hoje opera e fornece água a várias casas, mesmo após a instalação da rede oficial de abastecimento de água pela Companhia Estadual de Água e Esgoto (CEDAE) durante os anos 1980. Participamos nos anos 2014 e 2015 das diversas atividades da sociedade, tais como as reuniões mensais, a limpeza anual do reservatório, as atividades periódicas de manutenção da rede de água e o churrasco de fim de ano. As reuniões acontecem todo segundo domingo do mês, às $8 \mathrm{~h}$ da manhã. A presença dos membros é estritamente controlada pela assinatura obrigatória no livro de atas. O livro relata também a contabilidade da sociedade, com os valores arrecadados e os gastos com a compra de materiais para a realização dos trabalhos de manutenção da rede. Em caso de ausência de um dos membros sem

\footnotetext{
${ }^{5}$ Os residentes utilizam o termo "sociedade", mas são mais como associações sem fins lucrativos.

${ }^{6}$ Entrevista com o Sr. Francisco, residente do Morro da Formiga e membro mais antigo da Sociedade Bela Vista (Agosto de 2015).
} 
uma razão válida, pode lhe ser aplicado uma multa. ${ }^{7}$ Além disso, os membros devem estar preparados para participar pessoalmente nos trabalhos de manutenção da rede, bem como na lavagem anual do reservatório durante a reunião do mês de outubro. A manutenção da rede coletiva compreende os canos, que conectam a fonte da sociedade na mata até o reservatório da sociedade, situado já próximo das casas da favela. ${ }^{8}$ A manutenção dos canos que conectam cada casa ao reservatório é de responsabilidade de cada associado.

As reuniões da sociedade são um espaço muito masculino, mas participamos de reuniões com mulheres também. Nas reuniões que comparecemos, nunca estiveram todos os 15 associados. Além de participar da reunião mensal e colaborar nos trabalhos coletivos de manutenção da rede de água, cada associado deve pagar uma taxa, que era de 5 reais em 2015. Há sempre uma ameaça de cortar o "bico" (o acesso do cano do associado ao reservatório da sociedade) para aqueles que não cumprirem tais obrigações, mas nunca presenciamos o corte e nos parece que tal ameaça era mais um recurso para forçar a participação sem ser uma ameaça concreta. A Sociedade Bela Vista não aceita novos membros além dos 15 associados. No entanto, é possível vender um bico. Presenciamos, em uma das reuniões, a admissão de um novo membro, que comprou o direito de utilizar o cano de água de outro membro a um custo de 2500 reais. Desta forma, pode-se vender o seu acesso à água sem vender sua casa ou vice-versa. Basta conduzir o seu cano proveniente do reservatório para a sua nova casa. Essa realidade traz particularidades na paisagem da favela, já que é comum ver um emaranhando de canos, que cortam a favela, muitos inclusive de forma aérea, como cabos de eletricidade.

O saldo das contribuições mensais é utilizado no final do ano para um churrasco. Desta forma, a caixa da sociedade é esvaziada todos os anos. Durante as reuniões a que assistimos, notamos uma preocupação crescente com a escassez de água. Durante o longo período de estiagem de 2014/2015, os residentes salientaram a importância de utilizar a água com moderação, controlando o consumo e fiscalizando rigorosamente o desperdício de água pelos associados. Observamos um notável esforço coletivo de gerir um recurso escasso diante da diminuição das chuvas durante esses anos, o que dialoga com a crítica de Ostrow (1990) à tragédia dos comuns (HARDIN, 1968).

A organização dos participantes da sociedade de água Bela Vista demonstra um elevado nível de especialização técnica na construção da rede, bem como uma organização complexa para a sua gestão. Trata-se portanto de um esforço coletivo para o abastecimento de água, cujo custo se limita à manutenção da rede, sem qualquer comoditização do serviço. A informalidade aqui permitiu o acesso a recursos que historicamente têm sido negados ou precariamente oferecidos aos moradores

\footnotetext{
7 As razões válidas para a ausência são doença ou trabalho. Os membros devem comunicar a sua ausência com antecedência.

${ }^{8}$ A fonte da sociedade Bela Vista não se localiza muito longe da favela. Basta uns dez minutos de caminhada desde o reservatório da sociedade. Esse se localiza na parte superior da favela, no início da floresta.
} 
das favelas. O esforço por parte dos residentes para manter o bom funcionamento destas redes alternativas, mesmo depois de as casas estarem conectadas à rede pública, é digno de nota. A Companhia Estadual de Água e Esgotos (CEDAE) construiu reservatórios no topo dos morros, o que exige a instalação de bombas para elevar a água da rede pública até esses reservatórios. A manutenção efetuada pela CEDAE ou, por vezes pela própria prefeitura é extremamente deficiente. Moradores nos relataram que a reparação da bomba d'água pode levar dias, mesmo semanas, o que afeta o abastecimento de água das casas. A precariedade do acesso a água foi aliás frequentemente evocada como um dos maiores desafios para a prevenção contra o coronavírus. Como exigir medidas de limpeza com acesso intermitente à água. Assim, ser membro de uma sociedade de água é a garantia que não faltará água.

Para além deste aspecto concreto, observamos que o forte empenho dos moradores em manter o funcionamento da sociedade revela a importância dessas redes informais como organização de práticas sociais. As reuniões mensais, os mutirões de manutenção da rede, a lavagem do reservatório ou os churrascos de fim de ano pontuam o cotidiano de moradores. A materialidade dos canos de água acumula práticas sociais e por eles não passa somente água, mas também memórias e saberes. Os moradores nos revelaram a dificuldade e a angústia de não conseguir envolver seus filhos na gestão das sociedades de água. Alguns deles admitiam que seus filhos provavelmente não sabiam por onde passavam os canos de água. Explicaram que após a chegada da água da CEDAE, nos anos 1980, as gerações mais jovens não compreendiam mais a dificuldade em instalar uma rede de água. As redes informais de água da favela da Formiga refletem a importância da materialidade na constituição do cotidiano e das práticas sociais locais. Como sublinha Macfarlane (2011, p. 660), a produção da habitação e de sua espacialidade enfatiza a relação entre os aspectos materiais e o agenciamento dos moradores na produção da cidade. A luta pelo fornecimento deste recurso forjou a sociabilidade local, as redes de vizinhança e mesmo as lógicas de planejamento da favela. Como sustenta Korling (2020, p. 25), a materialidade da infraestrutura não exerce somente um papel central na produção do espaço urbano, mas também na mediação de subjetividades políticas.

\section{DEFINIÇÃO ESPACIAL DE LUGARES INFORMAIS}

A política de zoneamento tem por objetivo definir usos e funções específicas para os distintos espaços urbanos. No entanto, como defende Melé (2011, p. 19), as categorias introduzidas pelas qualificações jurídicas não vêm do espaço e das suas qualidades, mas das categorias de ação e do próprio direito como sistema de qualificação. Este sistema de qualificação baseia-se, por sua vez, nas decisões dos órgãos administrativos em definir os limites, usos e conteúdo do zoneamento. Se o zoneamento acaba conformando os espaços, as práticas sociais muitas vezes resistem e subvertem 
funções definidas pelo zoneamento. Com base em pesquisa realizada em 2013 sobre a regulamentação do comércio nas favelas do Rio de Janeiro, esta última parte do artigo aborda a questão da concessão de isenção dos alvarás para os estabelecimentos comerciais em áreas de favelas, o que traz a dificuldade material de demarcar fronteiras entre o formal e o informal. A qualificação jurídica das favelas como espaço informal pode paradoxalmente assegurar recursos aos favelados.

Apesar de consideradas ilegais e de serem objeto de políticas de urbanização, o governo do então Estado da Guanabara promulgou o Decreto n ${ }^{\circ} 1.668$ de 8 de Maio de 1963, a primeira tentativa de regular as atividades comerciais no interior das favelas. O paradoxo é a tentativa dos poderes públicos de formalizar tais atividades sem reconhecer os espaços, onde elas eram realizadas. $\mathrm{O}$ preâmbulo deste decreto afirmava:

Na medida do crescimento dos núcleos de favelados, instalaram-se, dentro deles, diferentes
locais de venda de produtos ou serviços, os quais a exemplo das habitações, contrariam ou
ignoram as leis e portarias a que devem sujeitar-se. Essas biroscas - nome dado às tascas,
botequins, tavernas, construídas nas favelas - apresentam diferentes modalidades de
comércio, inteiramente à revelia das normas e posturas do Estado. A fiscalização não se
exerce sobre tais atividades, porque receia dar legitimidade a serviços irregularmente
instalados. Trata-se como se não existissem. Entretanto, milhares de biroscas servem a
grande parte da população e concorrem com o comércio legalizado. O seu movimento de
vendas representa considerável parcela das operações do gênero e é praticado, sem nenhuma
razão válida, com tácita isenção de tributos. Por outro lado, as pessoas que nelas trabalham
não têm qualquer garantia.

Embora salientando a importância econômica destas atividades e a possibilidade de derivarem contribuições fiscais consideráveis através da tributação destas atividades, as autoridades procuraram evitar qualquer reconhecimento oficial das mesmas, o que as levou a uma manobra jurídica complexa, como demonstra a seguinte conclusão no preâmbulo do referido decreto:

"É certo que, sem admitir a regularidade de tal comércio, não pode o Estado ignorá-lo. Pode e deve, em benefício da população, especialmente da que dele diretamente se serve, orientar, fiscalizar e tributar atos de comércio que se relacionam com cerca de um terço da população do Estado."

A fim de conciliar a cobrança de impostos pelas autoridades públicas e a recusa em reconhecer legalmente este comércio, o artigo 1.1 do referido decreto empreendeu uma verdadeira "bricolagem jurídica", já que estabelecia que qualquer alvará de localização concedido aos comerciantes seria "a título precário por se tratar de favela". Assim, a imposição de uma qualificação jurídica de determinado espaço como área de favela constituía uma realidade jurídica sui generis, já que se oficilializava a própria informalidade com repercussões concretas nas práticas sociais e políticas nesses espaços, reafirmando, mais uma vez, a noção de precariedade vinculada às favelas. Esse estatuto precário das licenças municipais para as atividades econômicas perduram inacreditavelmente até aos dias de hoje, conforme demonstraremos, a seguir, através da evolução da legislação sobre comércios em favelas. 
O Decreto Municipal n. ${ }^{\circ} 15.214$ de 25 de Outubro de 1996 voltou a regulamentar o comércio em favelas e determinou que, nesses espaços, "o Alvará de Autorização Especial será concedido sempre a título precário e poderá se revogado ou cancelado a qualquer tempo por motivo de conveniência e oportunidade ou em caso de funcionamento em desconformidade com a legislação em vigor." (artigo $6^{\circ}$ ). Além de sublinhar o poder discricionário da prefeitura, este decreto reforçou a mesma natureza precária e provisória dos alvarás comerciais nas favelas. A Lei Municipal n. 2960 de 30 de dezembro de 1999, por sua vez, definiu que a licença para o estabelecimento e o funcionamento de atividades econômicas em favelas será concedida em caráter precário, tal como o artigo 21 do Decreto Municipal n. ${ }^{\circ} 18.989$ de 25 de Setembro de 2000, que especificou que o alvará de Autorização Especial será concedido sempre que determinado tipo de licenciamento for considerado precário em decorrência da natureza da ocupação - como as favelas, por exemplo- ou da atividade.

Alguns anos depois, o Decreto n. ${ }^{\text {o } 25.536, ~ d e ~} 12$ de Julho de 2005, definiu procedimentos e autorizou a aplicação da isenção da Taxa de Licença para Estabelecimento relativa ao exercício de atividades econômicas e outras de qualquer natureza em favelas. $\mathrm{O}$ artigo $2^{\circ}$ do supracitado decreto estabeleceu que após a análise dos documentos exigidos na legislação, as Inspetorias Regionais de Licenciamento e Fiscalização deveriam conceder o Alvará de Autorização Especial com dispensa do pagamento da Taxa de Licença para Estabelecimento para os imóveis localizados em favelas. O parágrafo único desse artigo estabeleceu que:

Sempre que houver incerteza quanto à localização de estabelecimento em área de favela, antes da decisão sobre a concessão de que trata o caput, a Coordenação de Licenciamento e Fiscalização consultará o órgão competente da Secretaria Municipal de Urbanismo a fim de obter a informação correspondente.

Mais recentemente, o Decreto n. $^{\circ} 35.388$, de 3 de abril de 2012, alterou o decreto $n^{\circ} 29.881$ de 18 de setembro de 2008 e estabeleceu que todo licenciamento em favelas será efetivado por meio da concessão de Alvará de Autorização Especial, em decorrência da natureza precária da ocupação. Estabeleceu, ainda, no artigo 38, que o alvará concedido em áreas de favela não implica o reconhecimento de regularidade do estabelecimento quanto a quaisquer normas aplicáveis ao seu funcionamento, à localização do imóvel ou às condições da edificação. Como se pode notar, a mesma "bricolagem jurídica" se manteve. Os poderes públicos, conforme demonstra o conjunto da legislação acima, regulamentam atividades econômicas, atuando planamente no campo da informalidade.

Nossa pesquisa sobre comércio em favelas procurou compreender os gargalhos para a formalização de certas atividades econômicas nas favelas através do estatuto de Micro Empreendedores Informais (MEI). Os MEIs são pessoas jurídicas, podem emitir notas até determinado valor/ano e possuem um regime fiscal extremamente vantajoso. Apesar de alguns 
MEIS em favelas necessitarem emitir notas, observamos que o elemento preponderante para se constituir como MEI é o acesso aos direitos previdenciários mínimos por um custo extremamente baixo. Para se constituir como MEI, é preciso obter a licença municipal para atividades econômicas, que, como mencionamos acima, são isentas em áreas de favelas.

É preciso salientar, que a legislação comercial acima mencionada não utiliza o zoneamento das Áreas de Especial Interesse Social (AEIS) ${ }^{9}$, que são delimitadas no espaço quando criadas. A utilização vaga de áreas de favela necessita, por vezes, ser melhor "espacializada", isto é, indicada no espaço de modo objetivo, a cada momento em que é aplicada. Trata-se obviamente de espaços com contornos amplamente variáveis. Parte dos microempreendedores que entrevistamos, que consideravam ter seu estabelecimento situado em áreas de favelas, foram surpreendidos com a informação da prefeitura à sua solicitação de que o endereço pesquisado "não era situado em favela". Em alguns casos, num determinado logradouro, um lado do mesmo era considerado área de favela, enquanto o outro não. Outra hipótese é a de um determinado logradouro ser considerado como área de favela até certo trecho, e daí para frente não. Muitas dessas áreas não são consideradas favelas no zoneamento oficial, mas quando visitadas pelos fiscais da prefeitura era constatado, que não apresentavam qualquer distinção morfológica ou socioeconômica entre as áreas consideradas como favela ou não.

Embora os limites entre favelas e bairros ditos formais sejam mais facilmente identificados nas zonas nobres da cidade, sobretudo na Zona Sul, esta situação difere consideravelmente nas favelas mais periféricas. Nesses espaços, a materialidade das construções e as práticas sociais se assemelham entre favelas e os bairros adjacentes e, muitas vezes, as áreas das favelas tendem a se espalhar por áreas, que eram outrora consideradas formais. A isenção fiscal para as licenças diz respeito apenas às atividades comerciais em espaços de favelas. Assim, paradoxalmente, para os microempreendedores individuais, estar localizado numa favela dar-lhes-ia a isenção para obter a licença municipal, que não obteriam em um bairro considerado formal.

Alguns interlocutores nos relataram, que só se deram conta que estavam em um bairro oficialmente formal, quando receberam a negativa da prefeitura em conceder a isenção da licença, já que, pelo zoneamento, estavam oficialmente em um bairro formal. Apesar de se espacializar, a informalidade é dinâmica e deve ser pensada como prática e não como espaços rigidamente delimitados. Estas práticas, por certo, não só têm lugar em locais específicos, como também produzem locais específicos (MACFARLANE, 2016, p. 71 e BOUDREAU et al., 2016, p. 10).

\footnotetext{
${ }^{9}$ As Áreas Especiais de Interesse Social (AEIS), também chamadas de Zonas Especiais de Interesse Social (ZEIS) são áreas demarcadas no território de uma cidade, para assentamentos habitacionais de população de baixa renda (existentes ou novos). Devem estar previstas no Plano Diretor e demarcadas por legislação próprias. Como permitem flexibilizar a legislação urbanística das áreas assim demarcadas, as favelas objeto de políticas de urbanização são normalmente gravadas como AEIS para se iniciarem às obras.
} 
Como analisa Boudreau e Davis (2017, p. 158), espaços informais não devem mais ser compreendidos como objetos essencializados, mas compreendidos no contexto de processos relacionais articulando atores, espaços e temporalidades.

No caso das licenças comerciais nas favelas, observamos, pois, a dificuldade em apreender o dinamismo da produção do espaço através dessas práticas informais. Como salienta Lussault (2016, p. 28), a informalidade não é um subsistema marginal dentro do sistema urbano, mas sim um modo normal de produção, organização e funcionamento do mundo contemporâneo. A informalidade, acrescenta o autor, torna possível dar respostas adequadas e (relativamente) satisfatórias às necessidades de numerosas pessoas, e não apenas das mais desfavorecidas (LUSSAULT, 2016, p. 28).

\section{CONCLUSÃO}

A informalidade, como procuramos demonstrar brevemente neste artigo, exerce uma função social e pode ser um elemento importante no acesso aos recursos urbanos. A justaposição de materiais e intenções, mediada por temporalidades variáveis, conformam o espaço. No caso das favelas cariocas, a informalidade pode permitir o acesso a áreas privilegiadas da cidade, que não seriam possíveis via mercado ou políticas estatais. Permite, ainda, logicas mais funcionais e adaptadas às necessidades dos moradores, sendo, indiretamente e paradoxalmente, um recurso dos moradores para acessar a cidade. Campanhas internacionais de combate as favelas ${ }^{10}$ podem estimular tanto a erradicação quanto a "inclusão", através da regularização fundiária, via mercado dessas áreas. O que procuramos reforçar aqui é que favelas não podem ser compreendidas como algo a ser eliminado ou suplantado como uma simples etapa de uma pretensa evolução urbana. As favelas fazem parte da história da cidade do Rio de Janeiro e certamente do seu futuro. As políticas públicas nestes espaços são tão necessárias quanto urgentes, mas devem partir de uma reflexão mais detalhada sobre as práticas que compensam no terreno a falta de infraestruturas e de um quadro legal que assegure o direito à cidade.

A informalidade em si não é o elemento a ser combatido e as políticas podem melhorar as condições de vida nesses bairros. Os esforços de formalização de atividades econômicas ou de regularização fundiária devem compreender a complexidade da informalidade. Apoiamo-nos na reflexão de Turner (1972, p. 274), defendendo que as políticas públicas em relação aos espaços informais devem ter um corte heterodoxo, ou seja, tais políticas não devem suprimir o que a população faz por sua própria iniciativa nem o suplantar. Devem, ao contrário, promover um diálogo

10 Ver, por exemplo, a campanha Cities without slums, que conta com o apoio da ONU. Ver: http://www.citiesalliance.org/cws-action-plan 
crítico com tais iniciativas, baseando-se no imenso recurso que essas iniciativas representam.

\section{REFERÊNCIAS}

ALLAIN, S. Introduction. Natures Sciences Sociétés, n. 19, p. 379-381, 2011.

BANKS, N.; LoOMBARD, M.; MITLIN, D. Urban Informality as a Site of Critical Analysis. The Journal of Development Studies, n. 56, p. 223-238, 2020.

BARTOLINI, F. Roma borghese: la casa e i ceti medi tra le due guerre. 1. ed. Roma: GLF Editori Laterza, 2001. 296p.

BASUDEB, G. K.; KANBUR, R.; OSTROW, E. Beyond informality and formality. In: BASUDEB, G. K.; KANBUR, R.; OSTROW, E. Linking the Formal and Informal Economy: Concepts and Policies: New York, Oxford University Press, 2006. p. 1-18.

BAUTÈS, N. ; MORELLE, M. ; FELTRAN, G. S. Espaces urbains et informalité politique au Brésil. Revue Confins, n. 28, 2016.

BEMMERGUI, L.; GONÇALVES, R. S. Urbanism miliciano in Rio de Janeiro: Nacla: Reports on the America, n. 51, p. 379-385, 2019.

BOUDREAU, J. A.; DAVIS, J. A. Introduction: A processual approach to informalization, Current Sociology Monograph, n. 65, p.155-161, 2017.

BOUdREAU, J. A.; LESEMANN, F.; MARTIN, C. Présentation : l'État en processus d'informalisaton, Lien social et Politiques, n. 76, p. 3-23, 2016.

CARVALHO, M. A transformação da política na favela: desconstruindo a "ausência do Estado, Revista Antropolítica, n. 38, p. 299-319, 2015.

CAVALCANTI, M. Do barraco à casa. Tempo, espaço e valor(es) em uma favela consolidada, Revista Brasileira de Ciências Sociais, v. 24, n. 69, p. 69-80, 2009.

CONN, S. The squatters' rights of favelados. 1. ed. n. 32. CIDOC (Centro Intercultural de documentacion), 1969. 142p.

CUNHA, M. I. Formalidade e informalidade. Questões e perspectivas. Etnográfica, v. 10, n. 2, p. 219-231, 2006.

DAS, V.; POOLE, D. (Org), Anthropology in the margins of the state. 1. ed. Santa Fe: School of American Research Press, 2004. 346p.

FAIRBANKS, R. P. The Politics of Urban Informality in Philadelphia's Recovery House Movement. Urban Studies, n. 48, p. 2555-2570, 2011.

FOURCAUT, A. La banlieue en morceaux. La crise des lotissements défectueux en France dans l'entre- deux-guerres. 1. ed. Paris: Éditions Créaphis, 2000. 339p. 
FRANCO, C. Controvérsias: entre o "direito de moradia" em favelas e o direito de propriedade imobiliária na cidade do Rio: o "direito de laje em questão". 1. ed. Rio de Janeiro: Topbooks, 2012. 286p.

GONÇALVES, R. Da política da 'contenção' à remoção: aspectos jurídicos das Favelas Cariocas. In: MELLO, M.; SILVA, L.; SIMÔES, S. (Ed). Favelas Cariocas: ontem e hoje. Rio de Janeiro: Editora Garamond, 2012. p. 253-278.

GONÇALVES, R. S. As favelas do Rio de Janeiro. História e Direito. 1 ed. Rio de Janeiro: Editoras PUC e Pallas, 2013. 408p.

GONÇALVES, R. S. L'informalité comme une ressource urbaine ? Le cas des favelas de Rio de Janeiro. EchoGeo, n. 39, p. 1-16, 2017.

GONÇALVES, R. S. Censos e favelas cariocas: evolução de um conceito censitário. Anais do Museu Paulista, v. 28, p. 1-30, 2020.

GONÇALVES, R. S.; PESSANHA, M. MORORÓ, G. Pelo Direito de Permanecer: mobilização política e o acesso a serviços de água e luz nas favelas cariocas no período pós-Estado Novo, Libertas, n. 15, p. 1-22, 2015.

GONÇALVES, R. S. BAUTÈS, N.; MANEIRO, M. Informalidade Urbana em Questão. Revista O Social em Questão, n. 42, p. 9-26, 2018.

GUIMARÃES, A. P. As favelas do Distrito Federal. Revista Brasileira de Estatística, n. 55, p. 250-278, 1953.

HAID, C. The Janus face of urban governance: State, informality and ambiguity in Berlin. Current Sociology Monograph, n. 65, p. 289-301, 2017.

HARDIN, G. The Tragedy of the Commons, Science, n. 3859, p. 1243-1248, 1968.

HARRINGTON, M. La Cultura de la pobreza en los Estados Unidos. 1 ed. Ciudad do México: Fondo de Cultura económica: México, 1963.243p.

IBGE. VIII Recenseamento Geral. Instruções para delimitação dos setores censitários, Rio de Janeiro: IBGE, 1970.

IPEME - INSTITUTO DE PESQUISAS E ESTUDOS DE MERCADO. Favelas e favelados do DF, Rio de Janeiro: lpeme, 1957.

JACQUOT, S .; SIERRA, S. ; TADIE, J. Informalité politique, pouvoirs et envers des espaces urbains, Espace Politique, n. 29, 2016.

JAGLIN, S. ; ZÉRAH, M. H. Eau des villes : repenser des services en mutation. Introduction. Revue Tiers Monde, n. 203, p. 7-22, 2010.

KORLING, G. Bricks, Documents and Pipes: Material Politics and Urban Development in Niamey, City \& Society, n. 32, p. 23-46, 2020.

KOWARICK, L. O capitalismo e marginalidade na América Latina. 2. ed. Rio de Janeiro: Paz e Terra, 1975. 188p. 
KOWARIC, L. A espoliação urbana. Rio de Janeiro, Paz e Terra, 1979. 202p.

LARSON, J. E. Informality, Illegality, and Inequality. Yale Law \& Policy Review, v. 20, n. 1 p. 137-182, 2002.

LEEDS, A.; LEEDS, E. A sociologia do Brasil urbano.1 ed. Rio de Janeiro: Zahar editores, 1978. 430p.

LEFEBVRE, H. O Direito à Cidade, Centauro Editora, São Paulo, 2001. 144p.

LEWIS, O. La cultura de la pobreza. Barcelona: Editorial Anagrama, 1972.

LUSSAULT, M. Présentation du dossier Urbanités informelles. Introduction. Tous urbains, n. 15, p. 28-33, 2016.

LAUTIER, B. Discussion (suite) notes d'un sociologue sur l'usage de la notion de «marge» dans les sciences sociales du développement. Revue Tiers Monde, v. 1, p. 17-20, 2006.

MACFARLANE, C. The city as assemblage: dwelling and urban space, Environment and Planning, Society and Space, n. 29, p. 649-671, 2011.

MACFARLANE, C. Repenser l'informalité : la politique, les crises et la ville, Lien social et Politiques, $\mathrm{n}^{\circ}$. 76, p. 44-76, 2016.

MAGALHÃES, A. O direito das favelas. 1. ed. Rio de Janeiro: Letra Capital, 2013. 493p.

MARICARO, E. Para enender a crise urbana. 1. ed. São Paulo: Expressão Popular, 2015. 116p.

MANGIN, W. Latin American Squatter Settlements: A Problem and a Solution. Latin. American Research Review, n. 3, p. 65-98, 1967.

MAR, J. M. Migration and urbanization: the barriada of Lima - an example of integration in urban life. In: HAUSER, P. (Org.). Urbanization in Latin America. New York: Unesco, 1962. p.170-189.

MELÉ, P. Transactions territoriales. Patrimoine, environnement et actions collectives au Mexique. 1. ed. Tours: Presses Universitaires François-Rabelais, 2011. 216p.

MORELlE, M. ; JACQUOT, S. ; TADIE, J. ; BAUTÈS, N. ; BÉNIT-GBAFFOU, C. ; MACCAGLIA, F. ; RIVELOIS, J. ; SIERRA, A. L'informalité politique, en ville. 8 chercheurs et 9 villes face aux modes de gouvernement urbain. Espace Politique, n. 29, 2016.

NÉLISS, C.; HERSCOVICI, A. ; MOULIN, M. Les formes de l'informel. Lien social et Politiques, n. 32, p. 5-13, 1994.

OSTROM, E. Governing the commons: the evolution of institutions for collective action. 1. ed. Cambridge: Cambridge University Press, 1990. 280p.

PERLMAN, J. O mito da marginalidade. Favelas e Política no Rio de Janeiro. 2. ed. Rio de Janeiro: Paz e Terra, 1981. 377p.

REIMERS, C. El fenómeno de la informalidad en periferias urbanas de los Estados Unidos de América, Módulo Arquitectura CUC, n. 14, p. 33-53, 2015. 
ROLNIK, R. Guerra dos lugares. A colonização da terra e da moradia na era das finanças. 1. ed. São Paulo: Boitempo, 2015. 411p.

ROY, A.; ALSAYYAD. Urban Informality: Transnational Perspectives from the Middle East, Latin America and South Asia. 1. ed. Lexington books: Berkeley, 2003. 352p.

ROY, A. The 21st-Century Metropolis: New Geographies of Theory, Regional Studies, v. 43, n. 6 , p. 819-830, 2009.

ROY, A. Why India cannot plan its cities: informality, insurgence and the idiom of urbanization, Planning Theory, n. 8, p. 76-87, 2009.

SANTOS, B. The Law of the Oppressed: The Construction and Reproduction of Legality in Pasargada. Law and Society Review, v. 12, p. 5-126, 1977.

SILVA, J. V.; GONÇALVES, R. S.; SANCHEZ, C. As sociedades de água: a educação ambiental comunitária em uma favela do Rio de Janeiro. Ensino, Saúde e Ambiente, v. 11, n. 3, p. 167-185, 2018.

SILVA, L. A. M. A política da favela. Cadernos Brasileiros, v. 9, n. 41, p. 35-47, 1967.

SULLIVAN, E.; OLMEDO, C. Informality on the urban periphery: Housing conditions and self- help strategies in Texas informal subdivisions. Urban Studies, v. 52, n. 6, p. 1037-1053, 2015.

TURNER, J. Colonização de terras devolutas nos países em desenvolvimento. In: MOYNIHAN, D. O desafio urbano. São Paulo: Editora Cultrix, 1972. p. 262-275.

VALLADARES, L. A Gênese da Favela carioca. A produção anterior às ciências sociais. Revista Brasileira de Ciências Sociais, v. 15, n. 44, p. 5-34, 2000.

VILLAR, O. M.; LAFOY, P. P.; URIBE-ECHEVARRÍA, F. La Marginalidad Urbana: Origen, proceso y modo. Resultados de una encuesta en poblaciones marginales del Gran Santiago. 1. ed. Buenos Aires: DESAL, 1970. 291p.

VORMS, C. Bâtisseurs de banlieue à Madrid. Le quartier de la Prosperidad (1860-1936). 1. ed. Paris : Éditions Créaphis, 2012. 368p. 